\title{
Editorial
}

\section{Importance of Asia in Post-COVID-19 World}

\section{By: Diaa Rashwan Chairman of the State Information Service}

The widespread outbreak of the Covid-19 pandemic and its successive waves in different regions of the world, is a phenomenon unwitnessed by the international community on recent spatial and temporal scale for many years.

Unfortunately, the effects of the pandemic outbreak have not been limited to health and therapeutic aspects, but also had profound economic, political, cultural, social and demographic implications, and the consequences of which will continue to affect all humanity for many years to come.

The Covid-19 pandemic has killed more than 1 million people, and fatalities continue to rise, especially with the beginning of the second wave, irrespective of varying age, socio-economic development, and scientific advances. This virus does not respect borders. It does not distinguish between races or ethnicities. It has no regard for a country's GDP or level of development. No country can fight against it with certainty and confidence.

At the same time, the socio-economic consequences of the pandemic are more serious and severe than its health effects despite the bitterness of loss of lives. Poverty and unemployment rates in all societies have increased, education and production systems, trade levels, consumption patterns and economic growth rates have fallen sharply worldwide, to the extent that only collaborative, multilateral solutions would put the international community back on its feet to pre-covid-19 levels, if humanity could defeat this epidemic, a matter not foreseen for months, perhaps years.

At the political level, the pandemic has had multiple implications, regarding both systems theory and international relations in political science, and the nature of the international system and the relations between its units. 


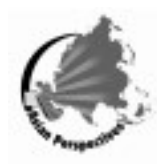

The crisis resulting from the covid-19 pandemic has restored consideration to the true duties of the State towards its citizens, revealing that the trends that exaggerated the call for the withdrawal of the State from its traditional functions in the areas of economy, business and trade in favor of market mechanisms are not only inhumane, but practically unsuccessful. Governments which were more aware of the social dimension and responsibility towards their citizens, were best able to mitigate the economic effects on their peoples, a matter which prompted all governments, including those which have clung to the capitalist approach at its most extreme, to intervene in the economic system and to take profound economic and social measures to protect their economies and to alleviate the financial distress on their citizens.

There is no doubt that this lesson will have implications for political thought in the field of political systems in the future.

In parallel with this development, there has been a similar realization concerning international relations and the nature of the global political and economic system. The pandemic has demonstrated the world's need for greater cooperation and solidarity not only in health sector and the search for a cure, but also in the economic sphere. Any single economy has proved unable to cope with the consequences of economic shutdown and the decline in world trade due to the spread of the coronavirus.

In both cases, regarding the nature of political and economic systems and domestic social policies, and in the domain of international economic and political relations, the Asian continent as a whole has proved to be the strongest and most economically resilient in the face of this international crisis, and also in the organized response to the pandemic and limiting its damage. In comparison, Europe and the United States were the most affected by the crisis at all health, economic and social levels.

In light of all this, the coronavirus crisis has increased the importance of Asian states in the international system, politically, scientifically and economically.

Such a realization existed before the pandemic outbreak, but covid-19 consequences helped accelerate and deepen it. To conclude... Asia is the continent of the future. 